\title{
Effect of sun exposure on cognitive function among elderly individuals in Northeast China
}

This article was published in the following Dove Press journal:

Clinical Interventions in Aging

\author{
Qian Gao' \\ Dechun Luan² \\ Xue Wang' \\ Shimeng Xin' \\ Yang Liu' \\ Jing $\mathrm{Li}^{\prime}$
}

'Department of Environmental Health, School of Public Health, China Medical University, Shenyang, People's Republic of China; ${ }^{2}$ Institute for Nutrition and Food Hygiene, Liaoning Provincial Center for Disease Control and Prevention, Shenyang, People's Republic of China
Correspondence: Qian Gao School of Public Health, China Medical University, No 77 Puhe Road, Shenyang North New Area, Shenyang, Liaoning Province II0I22, People's Republic of China

$\mathrm{Tel} / \mathrm{fax}+862431939406$

Email qgao@cmu.edu.cn
Background: Previous findings on the relationship between serum 25-hydroxyvitamin D [25(OH)D] level and cognitive impairment have been inconsistent. One reason is that serum $25(\mathrm{OH}) \mathrm{D}$ has a relatively short half-life, but the development of cognitive impairment is a longterm process. Skin exposure to solar ultraviolet radiation is the primary source of vitamin D synthesis. For this study, we hypothesized that people with different sun exposure behaviors would have different cognitive functions.

Methods: This study included 1,192 rural-dwelling elders in People's Republic of China whose sun exposure behaviors, including the duration of outdoor activities, use of sun protection, and time of day participants engaged in outdoor activities, were collected. Their global cognitive function was assessed by Mini-Mental State Examination (MMSE). Partitioning cluster analysis was used to classify participants into groups based on their sun exposure behaviors. Ordinal logistic regression analysis was used to examine the association between sun exposure and cognitive function.

Results: The participants were divided into high-, medium-, and low-sun-exposure groups by cluster analysis. The participants in the high-sun-exposure group had the longest sun exposure time, reported the least sun-protective behaviors, and usually spent time outdoors in the morning (8:00-11:00) and afternoon (13:00-16:00). The participants in the low-sun-exposure group had the shortest sun exposure time, had the most positive sun-protective behaviors, and mainly spent time outdoors in the early morning (6:00-8:00) and late afternoon (16:00-18:00). After adjusting for potential confounders, participants with habitually high sun exposure were more likely to have higher MMSE score (25.4) than those with habitually low sun exposure (MMSE score $=24.4$ ).

Conclusion: Long-term high sun exposure is positively related with better cognitive functioning.

Keywords: cognition, elderly, sun exposure behavior, People's Republic of China

\section{Introduction}

The possible relationship between vitamin $\mathrm{D}$ and cognitive function has gained attention because of the discovery of the vitamin D receptor and vitamin D hydroxylase in the brain. ${ }^{1,2}$ Data from animal and in vitro studies indicate that vitamin D plays a role in brain function by regulating neurotrophic factors, regulating neurotransmission, and affecting synaptic plasticity. ${ }^{3,4}$ However, population-based epidemiological studies have not drawn consistent conclusions on the link between serum vitamin D deficiency and cognitive impairment..$^{5-7}$ An important contributor to this inconsistency is the difficulty in measuring long-term individual vitamin D status. Serum 25-hydroxyvitamin D $[25(\mathrm{OH}) \mathrm{D}]$ concentration, an accepted index of vitamin D status, has a half-life of only approximately $2-3$ weeks. ${ }^{8}$ However, the development of cognitive impairment 
is a gradual and long-term process. Thus, using $25(\mathrm{OH}) \mathrm{D}$ to establish the relationship between vitamin $\mathrm{D}$ and cognitive function is inappropriate. Longitudinal or prospective studies may determine this relationship; however, such studies are difficult to carry out. Skin exposure to solar ultraviolet radiation (UVR) is the primary source of vitamin D synthesis. Sun exposure behaviors, such as taking sun-protective measures or gaining more sun exposure, have a substantial effect on evaluating individual long-term vitamin D status. Moreover, Kenborg et $\mathrm{al}^{9}$ reported that outdoor work was associated with a decreased risk of Parkinson's disease. Therefore, we hypothesized that people with more sun exposure would have better cognitive performance. In this study, we collected data on individual sun exposure behaviors and assessed cognitive function among rural-dwelling elderly population in Shenyang, a northeastern city in People's Republic of China.

\section{Materials and methods}

\section{Participants}

Participants were from the Sujiatun District (a rural suburb of the city of Shenyang, Liaoning province, $40^{\circ} \mathrm{N}, 123^{\circ} \mathrm{E}$ ) in Northeast China. Local residents who were native born and aged 60 years and over were invited to participate. Exclusion criteria included clinical diagnosis of dementia, Alzheimer's disease, Parkinson's disease, cerebral hemorrhage, or cerebral infarction within 6 months, inability to walk independently, and inability to understand or answer the study questionnaires. This study was approved by the ethics committee of China Medical University. All participants signed an informed consent form before participating in this study.

\section{Data collection}

Demographic factors, including age, gender, and total number of schooling years, were recorded. Body weight and height were self-reported, and body mass index $\left(\mathrm{kg} / \mathrm{m}^{2}\right)$ was calculated. History of hypertension and diabetes was also recorded. Lifestyle information included smoking history and alcohol consumption.

Participants were asked to summarize their sun exposure habits before age 60. Five questions were used to measure participants' sun exposure and sun-protective behaviors (Table S1). First, participants were asked the time of day they usually engage in outdoor activities (question 1). The response options were "6:00-8:00," "8:00-11:00," “11:00-13:00," "13:00-16:00," and “16:00-18:00." Participants could choose more than one response option. They were then asked how long they usually spent engaging in outdoor activities at daytime in winter (question 2) and in other seasons (question 3). The response options for these two questions were " $<0.5$ hour," "0.5-1 hour," " $1-3$ hour," "3-6 hour," and "more than 6 hours." The participants were also asked with the following questions: "When you were outside on sunny days, how often did you ..." “... wear long-sleeved clothes?" (question 4) and "... seek shade?" (question 5). For questions 4 and 5, the responses were measured on a five-point scale ranging from 1 (never) to 5 (always).

The consumption behavior for foods rich in vitamin D (including oily fish, eggs, liver, and mushrooms) before age 60 was recorded. The participants were also asked whether they had ever used vitamin D supplements before age 60 .

\section{Global cognitive function assessment}

The Mini-Mental State Examination (MMSE) was used to assess the participants' global cognitive performance. MMSE was originally developed by Folstein et al, ${ }^{10}$ and the Chinese version of MMSE used in this study was modified by Zhang et al. ${ }^{11}$ MMSE is a brief and widely used cognitive screening tool and is suitable for older populations. It consists of 30 items and assesses orientation, memory, attention and calculation, recall, and language. Scores range from 0 to 30, with higher scores indicating better cognitive function.

\section{Functional ability assessment}

The participants' functional ability was assessed by the Activity of Daily Living scale, ${ }^{12}$ which includes six items from the Physical Self-maintenance Scale and eight items from the Instrumental Activities of Daily Living. Each item was coded on a four-point scale ranging from 1 (independent) to 4 (totally dependent). Physical Self-maintenance Scale assesses the ability of toileting, eating, dressing, grooming, ambulation, and bathing. Instrumental Activities of Daily Living assesses the ability of using the telephone, shopping, preparing meals, doing housework, taking public transportation, washing clothes, handling finances, and taking medicines. Scores range from 14 to 56, with higher scores indicating greater impairment in functional capacity.

\section{Statistical analysis}

Partitioning cluster analysis was used to define three groups of participants on the basis of their sun exposure behaviors. One-way analysis of variance or $\chi^{2}$ test was used to compare the characteristics of the participants from the three sun exposure behavior groups (low-, medium-, and high-sunexposure groups). One-way analysis of variance, followed 
by Tukey's post hoc test, was used to compare the level of global cognitive function between the sun exposure behavior groups. Cognitive function was classified by tertiles of MMSE score: $2=$ "low" ( $\leq 23), 1=$ "medium" (24-27), and $0=$ "high" $(>27)$. Ordinal logistic regression was used to determine the association between sun exposure behavior and global cognitive function. All statistical analyses were performed using R software, version 3.4.0 (R Foundation, Vienna, Austria). All $P$-values were two sided, and values $<0.05$ were considered statistically significant.

\section{Results}

\section{Participant characteristics}

Among the 1,192 participants included in the analysis, $553(46 \%)$ were male; the mean participant age was $69.5 \pm 5.7$ years. The characteristics of the participants are summarized in Table 1.

\section{Cluster analysis}

Figure 1 shows the subgroup profiles among the sun exposure behavior groups. The participants in the high-sun-exposure group reported the least sun-protective behaviors, had the longest sun exposure time in both winter and other seasons, and usually spent time outdoors in the morning $(8: 00-11: 00)$ and afternoon (13:00-16:00). The participants in the lowsun-exposure group had the most positive sun-protective behaviors, had the shortest sun exposure time, and mainly spent time outdoors in the early morning $(6: 00-8: 00)$ and late afternoon (16:00-18:00).
Cognitive function by sun exposure group The MMSE score of the participants in the high-sun-exposure group was the highest (MMSE $=25.4$ ), followed by the MMSE scores of the participants in the low-sun-exposure group (MMSE $=24.4$ ) and the medium-sun-exposure group (MMSE $=24.2$; Figure 2). The difference in MMSE scores between groups was significant (high vs medium, $P<0.001$; high vs low, $P=0.045$ ), with the exception of the difference between the low- and medium-sun-exposure groups $(P=0.833)$.

\section{Participant characteristics by sun exposure group}

Table 1 shows the characteristics of the participants by sun exposure category. The participants in the high-sun-exposure group had shorter schooling years; had higher prevalence of hypertension; more likely smoked; used to consume less oily fish, eggs and mushrooms; and had higher prevalence of vitamin D supplement use $(P<0.05)$.

\section{Relationship between sun exposure behavior and cognitive function}

The results of the ordinal logistic regression analysis are shown in Table 2. No significant association was found between sun exposure behavior and cognitive function in the unadjusted model (model 1). In the regression model adjusted only for the total number of schooling years (model 2), the participants in the high-sun-exposure group

Table I Characteristics of participants by sun exposure category ${ }^{\mathrm{a}}$

\begin{tabular}{|c|c|c|c|c|c|}
\hline \multirow[t]{2}{*}{ Characteristics } & \multirow[t]{2}{*}{ Total } & \multicolumn{3}{|c|}{ Sun exposure group } & \multirow[t]{2}{*}{$P$-value ${ }^{b}$} \\
\hline & & Low & Medium & High & \\
\hline $\mathrm{N}$ & $\mathrm{I}, 192$ & 240 & 636 & 316 & \\
\hline Age, years & $69.5(5.7)$ & $69.6(5.8)$ & $69.7(5.7)$ & $69.0(5.7)$ & 0.159 \\
\hline Male, N (\%) & $553(46.4)$ & I IO (45.8) & $288(45.3)$ & I $55(49.1)$ & 0.537 \\
\hline Schooling years, years & $5.8(2.8)$ & $6.5(3.1)$ & $5.8(2.7)$ & $5.4(2.7)$ & $<0.001$ \\
\hline $\mathrm{BMI}, \mathrm{kg} / \mathrm{m}^{2}$ & $23.8(3.0)$ & $23.4(2.9)$ & $23.9(3.1)$ & $23.9(2.8)$ & 0.064 \\
\hline Hypertension, N (\%) & $484(40.6)$ & $90(37.5)$ & $247(38.8)$ & $147(46.5)$ & $0.04 I$ \\
\hline Diabetes, N (\%) & I3 $1(|| .0)$ & $22(9.2)$ & $65(10.2)$ & $44(13.9)$ & 0.137 \\
\hline Smoking, N (\%) & $368(30.9)$ & $59(24.6)$ & $201(31.6)$ & $108(34.2)$ & 0.044 \\
\hline Drinking, N (\%) & $349(29.3)$ & $67(27.9)$ & $188(29.6)$ & $94(29.7)$ & 0.873 \\
\hline ADL & $16.3(4.8)$ & $16.2(5.1)$ & $16.5(4.8)$ & $15.9(4.4)$ & 0.123 \\
\hline Oily fish, time/week & $0.8(0.8)$ & $0.8(0.6)$ & $0.8(1.0)$ & $0.6(0.6)$ & 0.004 \\
\hline Eggs, time/week & 4.I (3.6) & $5.3(3.7)$ & 4.I (4.0) & $3.3(2.3)$ & $<0.001$ \\
\hline Liver, time/week & $0.3(0.5)$ & $0.3(0.3)$ & $0.3(0.5)$ & $0.2(0.5)$ & 0.083 \\
\hline Mushrooms, time/week & $0.7(1.0)$ & $1.0(1.0)$ & $0.6(1.0)$ & $0.5(0.9)$ & $<0.001$ \\
\hline Vitamin D supplements use, N (\%) & $103(8.6)$ & $14(5.8)$ & $51(8.0)$ & $38(12.0)$ & 0.026 \\
\hline
\end{tabular}

Notes: ${ }^{V}$ alues are means (SD) unless otherwise noted. ${ }^{b}$-values are from one-way ANOVA or $\chi^{2}$ trend tests, as appropriate.

Abbreviations: ADL, Activities of Daily Living; ANOVA, analysis of variance; BMI, body mass index. 

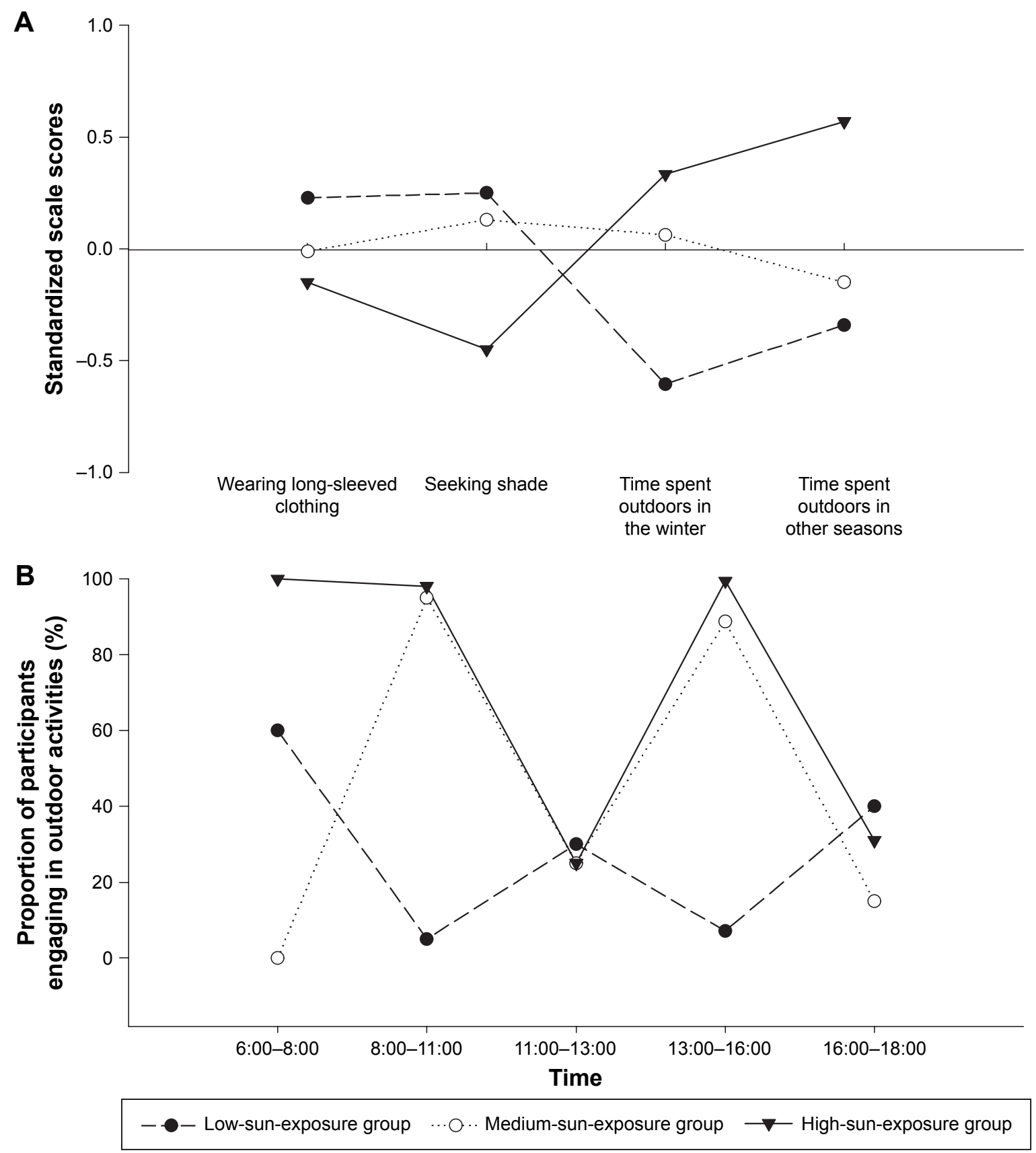

Figure I Three clustered sun exposure profiles on (A) sun-protective behaviors and time spent outdoors and (B) temporal distribution of outdoor activities.

were more likely to have better cognitive function than those in the low-sun-exposure group (OR: $0.56,95 \% \mathrm{CI}$ : $0.40-0.78$ ), but such a difference did not exist between the medium- and low-sun-exposure groups. After adjusting for all potential confounders, more sun exposure showed a progressive improvement in cognitive function (mediumsun-exposure group: OR: 0.85, 95\% CI: 0.61-1.18; highsun-exposure group: OR: $0.50,95 \%$ CI: $0.34-0.73$; $P$ for trend: 0.0014).

\section{Discussion}

In this study, we found that participants who had the longest sun exposure time, reported the least sun-protective behaviors, and usually spent time outdoors in the morning and afternoon prior to age 60 , were more likely to have better cognitive function.

Many large-scale cross-sectional studies have observed an association between low serum 25(OH)D concentrations and cognitive impairment. ${ }^{13,14}$ Although the assumption is 


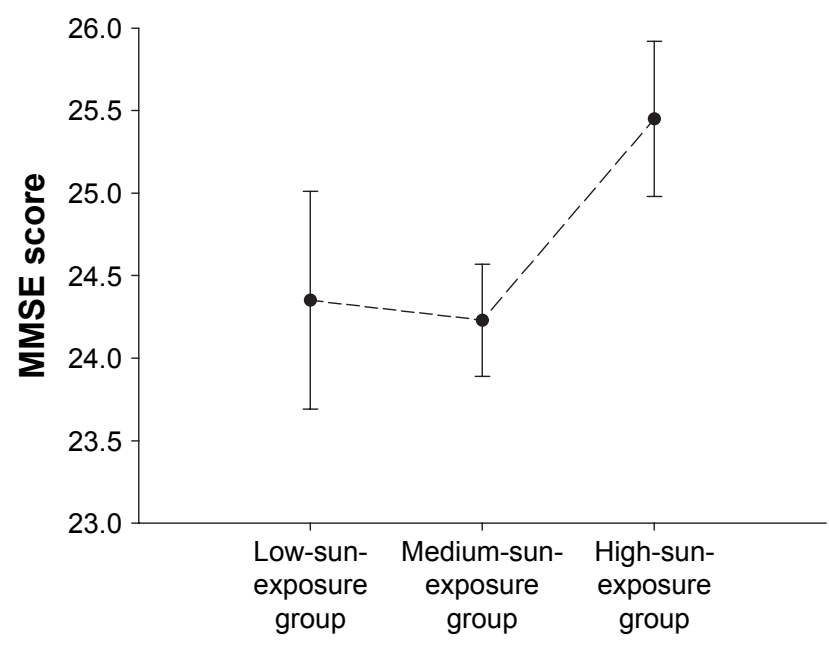

Figure 2 Distribution of MMSE scores among three sun exposure groups. Abbreviation: MMSE, Mini-Mental State Examination.

often that low vitamin D status leads to cognitive impairment, cognitive impairment may actually decrease serum vitamin $\mathrm{D}$ concentrations because of reduced individual outdoor activity and, thus, sun exposure. This is because cognitive impairment is usually accompanied by a decline in physical function and ability to perform everyday activities. ${ }^{15,16}$ Moreover, serum $25(\mathrm{OH})$ D concentration reflects vitamin D status over the past few weeks only. ${ }^{8}$ Collectively, these factors might result in inconsistent conclusions across studies. Because of the inherent challenges in long-term monitoring of individual vitamin D status in population-based surveys, in this study, we attempted to use an index to represent long-term vitamin D status.

Humans get vitamin D from sunlight exposure and diet. Many studies have explored the relationship between cognition and vitamin D from dietary intake, ${ }^{17-19}$ whereas few have examined vitamin $\mathrm{D}$ from sunlight exposure. ${ }^{9,20}$ Because traditional Chinese diet is low in vitamin $\mathrm{D}$ and few foods on the Chinese market are fortified with vitamin $D,{ }^{21,22}$ sun exposure is the most important source of vitamin $\mathrm{D}$ for residents in People's Republic of China. To date, no accepted index to evaluate long-term vitamin D status is available. In this situation, examining sun exposure behaviors is a feasible method of assessing vitamin D exposure from sunlight.

Some factors such as solar zenith angle, duration of skin exposure to sunlight, and area of the skin exposed can influence vitamin D synthesis in the skin. The solar zenith angle changes with latitude, time of day, and season. A study performed in Boston, which is at a similar latitude to Shenyang, showed that the effect of vitamin D synthesis during the day followed a bell-shaped curve, with the most effective exposure time observed around noon. ${ }^{23}$ In the present study, the percentage of participants who reported outdoor activity around noon (11:00-13:00) was comparable among the three sun exposure groups. The difference was that people in the high- and medium-sun-exposure groups were more likely to spend time outdoors in the morning (8:00-11:00) and afternoon (13:00-16:00). By contrast, those in the low-sun-exposure group engaged in more outdoor activities in the early morning (6:00-8:00) and late afternoon (16:00-18:00), during which time the synthesis of vitamin D in the skin is very low. Moreover, a study has found that at latitude above $35^{\circ}$, vitamin D synthesis in the skin during the winter months is very limited. ${ }^{24}$ In winter, the solar zenith angle in Shenyang (latitude $40^{\circ} \mathrm{N}$ ) is high. In addition, because of the low winter temperatures in Shenyang, residents dress warmly, and the exposed skin surface area is therefore very small. Consequently, almost no vitamin D can be synthesized in the skin during winter in Shenyang. The average daily outdoor activity time of the participants in the high-sun-exposure group was much longer than that of the participants in the other two groups, regardless of season. However, the difference between the medium- and low-sun-exposure groups was small in the three seasons, excluding winter. Thus, we can conclude that, compared with the participants in the low-sun-exposure group, those in the medium-sun-exposure group had no advantages in terms of vitamin D synthesis base on the duration of sun exposure.

Table 2 Results of ordinal logistic regression on the effect of sun exposure behavior on cognitive function

\begin{tabular}{|c|c|c|c|c|c|c|}
\hline \multirow{2}{*}{$\begin{array}{l}\text { Sun exposure } \\
\text { group }\end{array}$} & \multicolumn{2}{|l|}{ Model I } & \multicolumn{2}{|l|}{ Model 2} & \multicolumn{2}{|l|}{ Model 3} \\
\hline & OR & $95 \% \mathrm{Cl}$ & OR & $95 \% \mathrm{Cl}$ & OR & $95 \% \mathrm{Cl}$ \\
\hline Low & Reference & & Reference & & Reference & \\
\hline Medium & 1.19 & $0.90-1.58$ & 1.09 & $0.82-1.45$ & 0.85 & $0.61-1.18$ \\
\hline High & 0.73 & $0.53-1.01$ & 0.56 & $0.40-0.78$ & 0.50 & $0.34-0.73$ \\
\hline$P$ for trend & 0.0002 & & $<0.0001$ & & 0.0014 & \\
\hline
\end{tabular}

Notes: Model I: unadjusted. Model 2: adjusted for schooling years. Model 3: adjusted for schooling years, age, sex, BMI, hypertension, diabetes, ADL score, drink, smoke, diet intake and vitamin $D$ supplement use.

Abbreviations: ADL, Activities of Daily Living; BMI, body mass index. 
This may explain the absence of difference in cognitive function between the medium- and low-sun-exposure groups.

Sun-protective behaviors, which can reduce skin exposure to sunlight, affect vitamin D status. Wearing long-sleeved clothing and seeking shade may decrease serum 25(OH)D concentrations, ${ }^{25,26}$ but not frequent sunscreen use. ${ }^{27,28}$ Furthermore, in this study, few people reported "often" using sunscreen (10 of 1,192), and none reported "always" using sunscreen (data not shown). Therefore, among the sun-protective behaviors, only wearing long sleeves and seeking shade were taken into account. The results of the cluster analysis showed that the frequency of sun-protective behaviors was highest in the participants in the low-sun-exposure group. That might cause the participants in the low-sunexposure group to obtain less vitamin D from sunlight.

Among the participants in the high-sun-exposure group, longer exposure to solar UVR at a lower solar zenith angle and engaging in fewer sun-protective behaviors provided opportunities to synthesize more vitamin D in the skin. The findings of the present study have thus led us to believe that high levels of serum vitamin D sustained over a long term may contribute to better cognitive functioning. Moreover, vitamin $\mathrm{D}$ is important to cardiovascular health, ${ }^{29}$ and cardiovascular diseases are closely associated with cognitive impairment. ${ }^{30,31}$ We found that the participants in the low-sun-exposure group showed a higher MMSE score than those in the medium-sunexposure group (Figure 2). However, those in the low-sunexposure group had the highest number of school years among the three sun exposure groups, suggesting a confounding effect of education. After adjusting for the number of school years attended, the participants in the high-sun-exposure group were more likely to have better cognitive function than those in the low-sun-exposure group. When all potential confounders were adjusted, the protective effect trend of sun exposure on cognitive function was more obvious, with $P$ for trend of 0.0014 ; however, the participants in the mediumsun-exposure group still showed no statistically significant lower risk for poor cognitive function. Similar results were observed when compared with exclusive indoor work, participants with maximal outdoor work had decreased risks for Parkinson's disease, but participants with moderate outdoor work did not. ${ }^{9}$ A possible reason for the difference between the medium- and high-sun-exposure groups could be that the effect of sun exposure on cognition is only manifested when the level of sun exposure is sufficiently high.

The prevalence of mild cognitive impairment is currently high among elderly populations globally, ${ }^{32}$ and a high incidence of dementia has been found among individuals with mild cognitive impairment. ${ }^{33}$ At present, there is no effective cure for dementia. Family caregivers and patients themselves are often subject to great physical, emotional, and economic pressures. ${ }^{34}$ At the same time, vitamin D deficiency is a major public health issue worldwide. ${ }^{35}$ Determining the role of vitamin $\mathrm{D}$ in slowing cognitive impairment can help in preventing this disease. Considering the long process of cognitive impairment development, keeping adequate vitamin $\mathrm{D}$ level is necessary for all ages.

The main strength of this study is that all participants were from the same region, minimizing the effect of various ambient UVR levels. Our study had a relatively large sample size of over 1,100 participants, which has improved the statistical power of our analyses. Furthermore, functional ability was controlled in the logistic regression analysis, because participants who had less cognitive function tended to be less active.

This study had certain limitations. First, potential recall bias existed because data on sun exposure behaviors and frequency of consumption of vitamin D-rich food before age 60 were obtained using retrospective survey questions. Moreover, survey results revealed that some participants had low cognitive function. The memory of these participants may thus have been somewhat impaired, although they did not meet the clinical criteria for dementia and could respond to survey questions autonomously, but also induced recall bias. Second, although some potential confounding variables such as sociodemographic characteristics, clinical status, health behaviors, and dietary factors were adjusted in the analyses, not all potential confounders were considered. Finally, this study was performed in a Chinese population, and the generalizability of these results to other ethnic groups remains uncertain.

\section{Conclusion}

In conclusion, to the authors' knowledge, this is the first Chinese study to investigate the effect of sun exposure on cognition by evaluating individual sun exposure behaviors. The results demonstrate that participants with long-term high sun exposure have better cognitive functions. A hypothesis is that vitamin D may play a protective role.

\section{Acknowledgment}

This research was supported by National Natural Science Foundation of China (Grant No 81402644).

\section{Disclosure}

The authors report no conflicts of interest in this work. 


\section{References}

1. Sutherland MK, Somerville MJ, Yoong LK, Bergeron C, Haussler MR, Mclachlan DR. Reduction of vitamin D hormone receptor mRNA levels in Alzheimer as compared to Huntington hippocampus: correlation with calbindin-28k mRNA levels. Brain Res Mol Brain Res. 1992; 13(3):239-250.

2. Eyles DW, Smith S, Kinobe R, Hewison M, McGrath JJ. Distribution of the vitamin $\mathrm{D}$ receptor and 1 alpha-hydroxylase in human brain. J Chem Neuroanat. 2005;29(1):21-30.

3. Groves NJ, McGrath JJ, Burne TH. Vitamin D as a neurosteroid affecting the developing and adult brain. Annu Rev Nutr. 2014;34:117-141.

4. Garcion E, Wion-Barbot N, Montero-Menei CN, Berger F, Wion D. New clues about vitamin D functions in the nervous system. Trends Endocrinol Metab. 2002;13(3):100-105.

5. Anastasiou CA, Yannakoulia M, Scarmeas N. Vitamin D and cognition: an update of the current evidence. J Alzheimers Dis. 2014;42(Suppl 1): S71-S80.

6. Etgen T, Sander D, Bickel H, Sander K, Förstl H. Vitamin D deficiency, cognitive impairment and dementia: a systematic review and metaanalysis. Dement Geriatr Cogn Disord. 2012;33(5):297-305.

7. Miller JW, Harvey DJ, Beckett LA, et al. Vitamin D status and rates of cognitive decline in a multiethnic cohort of older adults. JAMA Neurol. 2015;72(11):1295-1303.

8. Haddad JG Jr, Rojanasathit S. Acute administration of 25-hydroxycholecalciferol in man. J Clin Endocrinol Metab. 1976;42(2):284-290.

9. Kenborg L, Lassen CF, Ritz B, et al. Outdoor work and risk for Parkinson's disease: a population-based case-control study. Occup Environ Med. 2011;68(4):273-278.

10. Folstein MF, Folstein SE, McHugh PR. "Mini-mental state". A practical method for grading the cognitive state of patients for the clinician. $J$ Psychiatr Res. 1975;12(3):189-198.

11. Zhang MY. Geriatric scale. In: Zhang MY, editor. Handbook of Rating Scales in Psychiatry. Changsha: Hunan Science and Technology Press; 1998:184-188. Chinese.

12. Wu WY. [Social and living function scale]. In: Zhang MY, editor. Handbook of Rating Scales in Psychiatry. Changsha: Hunan Science and Technology Press; 1998:166-168. Chinese.

13. Llewellyn DJ, Lang IA, Langa KM, Melzer D. Vitamin D and cognitive impairment in the elderly U.S. population. J Gerontol A Biol Sci Med Sci. 2011;66(1):59-65.

14. Lee DM, Tajar A, Ulubaev A, et al. Association between 25-hydroxyvitamin D levels and cognitive performance in middle-aged and older European men. J Neurol Neurosurg Psychiatry. 2009;80(7):722-729.

15. Tomaszewski Farias S, Giovannetti T, Payne BR, et al. Self-perceived difficulties in everyday function precede cognitive decline among older adults in the ACTIVE study. J Int Neuropsychol Soc. 2018; 24(1):104-112.

16. Atkinson HH, Rapp SR, Williamson JD, et al. The relationship between cognitive function and physical performance in older women: results from the women's health initiative memory study. J Gerontol A Biol Sci Med Sci. 2010;65(3):300-306.

17. Annweiler C, Schott AM, Rolland Y, Blain H, Herrmann FR, Beauchet O. Dietary intake of vitamin D and cognition in older women: a large population-based study. Neurology. 2010;75(20):1810-1816.
18. Andreeva VA, Whegang-Youdom S, Touvier M, et al. Midlife dietary vitamin $\mathrm{D}$ intake and subsequent performance in different cognitive domains. Ann Nutr Metab. 2014;65(1):81-89.

19. Rondanelli M, Trotti R, Opizzi A, Solerte SB. Relationship among nutritional status, pro/antioxidant balance and cognitive performance in a group of free-living healthy elderly. Minerva Med. 2007;98(6): 639-645.

20. Kent ST, Kabagambe EK, Wadley VG, et al. The relationship between long-term sunlight radiation and cognitive decline in the REGARDS cohort study. Int J Biometeorol. 2014;58(3):361-370.

21. Ma G, Hu X, Cui C, et al. Study on the current status and characteristics of food consumption among Chinese population. Food and Nutrition in China. 2007;7:4-5. Chinese.

22. Chang JL, Wang Y, editors. A Comprehensive Report on Chinese Nutrition and Health Surveillance 2010-2013. Beijing: Peking University Medical Press; 2016:42-43. Chinese.

23. Chen T, Lu Z, Holick M. Photobiology of vitamin D. In: Holick MF, editor. Vitamin D: Physiology, Molecular Biology, and Clinical Applications. 2nd ed. New York, NY: Humana Press; 2010:35-60.

24. Webb AR, Kline L, Holick MF. Influence of season and latitude on the cutaneous synthesis of vitamin D3: exposure to winter sunlight in Boston and Edmonton will not promote vitamin D3 synthesis in human skin. J Clin Endocrinol Metab. 1988;67(2):373-378.

25. Linos E, Keiser E, Kanzler M, et al. Sun protective behaviors and vitamin D levels in the US population: NHANES 2003-2006. Cancer Causes Control. 2012;23(1):133-140.

26. Hansen L, Tjønneland A, Køster B, et al. Sun exposure guidelines and serum vitamin D status in Denmark: the StatusD Study. Nutrients. 2016;8(5):266.

27. Norval M, Wulf HC. Does chronic sunscreen use reduce vitamin D production to insufficient levels? Br J Dermatol. 2009;161(4):732-736.

28. Libon F, Courtois J, Le Goff C, et al. Sunscreens block cutaneous vitamin $\mathrm{D}$ production with only a minimal effect on circulating 25-hydroxyvitamin D. Arch Osteoporos. 2017;12(1):66.

29. Mozos I, Marginean O. Links between Vitamin D deficiency and cardiovascular diseases. Biomed Res Int. 2015;2015:109275-12.

30. Iadecola C, Yaffe K, Biller J, et al. Impact of hypertension on cognitive function: A scientific statement from the American Heart Association. Hypertension. 2016;68(6):e67-e94.

31. Gorelick PB, Scuteri A, Black SE, et al. Vascular contributions to cognitive impairment and dementia: a statement for healthcare professionals from the american heart association/american stroke association. Stroke. 2011;42(9):2672-2713.

32. Roberts R, Knopman DS. Classification and epidemiology of MCI. Clin Geriatr Med. 2013;29(4):753-772.

33. Roberts RO, Knopman DS, Mielke MM, et al. Higher risk of progression to dementia in mild cognitive impairment cases who revert to normal. Neurology. 2014;82(4):317-325.

34. World Health Organization. Dementia: A Public Health Priority Geneva, Switzerland: World Health Organization; 2012.

35. Palacios C, Gonzalez L. Is vitamin D deficiency a major global public health problem? J Steroid Biochem Mol Biol. 2014;144(Pt A): $138-145$. 


\section{Supplementary material}

Table SI Questions on sun exposure habits

\begin{tabular}{|c|c|c|c|c|}
\hline \multicolumn{5}{|c|}{ I. What times of day you usually engage in outdoor activities? (You can choose more than one response option.) } \\
\hline 6:00-8:00 & $8: 00-11: 00$ & II:00-13:00 & $13: 00-16: 00$ & 16:00-18:00 \\
\hline \multicolumn{5}{|c|}{ 2. How long you usually spent engaging in outdoor activities at daytime in winter? } \\
\hline $\begin{array}{l}<0.5 \text { hour } \\
\text { (I) }\end{array}$ & $\begin{array}{l}0.5-I \text { hour } \\
(2)\end{array}$ & $\begin{array}{l}\text { I-3 hour } \\
\text { (3) }\end{array}$ & $\begin{array}{l}3-6 \text { hour } \\
\text { (4) }\end{array}$ & $\begin{array}{l}\text { More than } 6 \text { hours } \\
\text { (5) }\end{array}$ \\
\hline \multicolumn{5}{|c|}{ 3. How long you usually spent engaging in outdoor activities at daytime in other seasons? } \\
\hline $\begin{array}{l}<0.5 \text { hour } \\
\text { (I) }\end{array}$ & $\begin{array}{l}0.5-1 \text { hour } \\
\text { (2) }\end{array}$ & $\begin{array}{l}\text { I-3 hour } \\
\text { (3) }\end{array}$ & $\begin{array}{l}3-6 \text { hour } \\
\text { (4) }\end{array}$ & $\begin{array}{l}\text { More than } 6 \text { hours } \\
\text { (5) }\end{array}$ \\
\hline \multicolumn{5}{|c|}{ 4. When you were outside on sunny days, how often did you wear long-sleeved clothes? } \\
\hline $\begin{array}{l}\text { Never } \\
\text { (I) }\end{array}$ & $\begin{array}{l}\text { Seldom } \\
\text { (2) }\end{array}$ & $\begin{array}{l}\text { Sometimes } \\
\text { (3) }\end{array}$ & $\begin{array}{l}\text { Often } \\
(4)\end{array}$ & $\begin{array}{l}\text { Always } \\
(5)\end{array}$ \\
\hline \multicolumn{5}{|c|}{ 5. When you were outside on sunny days, how often did you seek shade? } \\
\hline $\begin{array}{l}\text { Never } \\
\text { (I) }\end{array}$ & $\begin{array}{l}\text { Seldom } \\
\text { (2) }\end{array}$ & $\begin{array}{l}\text { Sometimes } \\
\text { (3) }\end{array}$ & $\begin{array}{l}\text { Often } \\
(4)\end{array}$ & $\begin{array}{l}\text { Always } \\
(5)\end{array}$ \\
\hline
\end{tabular}

\section{Publish your work in this journal}

Clinical Interventions in Aging is an international, peer-reviewed journal focusing on evidence-based reports on the value or lack thereof of treatments intended to prevent or delay the onset of maladaptive correlates of aging in human beings. This journal is indexed on PubMed Central, MedLine,
CAS, Scopus and the Elsevier Bibliographic databases. The manuscript management system is completely online and includes a very quick and fair peer-review system, which is all easy to use. Visit http://www.dovepress. com/testimonials.php to read real quotes from published authors. 